\title{
As cidades são meios e os meios são as mensagens: uma leitura estético-política das reformas urbanas na América Ibérica durante a Belle Époque
}

Cities are media and media are the messages: an aesthetic-political reading of urban reforms in Iberian America during the Belle Époque

Marcos Alexandre Arraes ${ }^{\star}$

Matheus Falcão**

Palavras-chave:

Reformas Urbanas

Estética

Tecnopolítica

\begin{abstract}
Resumo: O presente artigo se propõe a demonstrar como a modernidade fez emergir, junto com o desejo de renovação urbana, uma lógica tecnopolítica hegemônica, condensada em princípios estéticos de caráter socialmente excludente. A narrativa se dá a partir de uma contextualização histórica das transformações urbanas no início da modernidade na Ibero-América e pontua a presença de um projeto tecnopolítico norteador dos princípios estéticos ali presentes. A narrativa foi construída a partir de apresentação de dados e provocações de ordem analítica, sem, contudo, deter-se em análises conceituais profundas.
\end{abstract}

Abstract: The current article aims to demonstrate how modernity has presented, along with the desire for urban renewal, the emergence of a hegemonic technicalpolitical project condensed into aesthetic program of a socially exclusive character. The narrative is based on a historical contextualization of urban transformations at the beginning of modernity in Ibero-America, highlighting the presence of a technical-political project that guides the aesthetic principles present there. The narrative was constructed through the presentation of data and provocations of analytical order, without, however, dwelling on deep conceptual analyzes.

Recebido em $1^{\circ}$ de outubro de 2018. Aprovado em 18 de fevereiro de 2019.
A História das reformas urbanas na América Latina ainda é um capítulo pouco explorado nos livros de história sobre a região. Apesar de na historiografia brasileira haver uma já consolidada tradição de estudos das modernizações ocorridas no Rio de Janeiro aos fins do Século XIX e início dos anos 1920, seguidos de alguns estudos isolados sobre capitais como São Paulo e Recife, são relativamente poucas as linhas dedicadas às transformações similares ocorridas no restante dos países ibero-americanos. Certamente essa ausência não se deve à inocorrência ou à irrelevância de processos reformistas similares nos países de colonização espanhola na América. Não objetivamos aqui desenvolver as razões dessa "negligência historiográfica"; mas, talvez, elas possam estar relacionadas às especificidades dos processos históricos dessas regiões, que produziram efeitos diferenciados em cada uma delas, tendo o caso brasileiro despertado maior atenção aos efeitos que emergiram da transformação nas bases político-sociais do Império diante do advento da República, história essa não compartilhada pelos nossos vizinhos das Américas.

Em estudo de referência sobre o tema, Arturo Almandoz demonstra que, entretanto, existia um desejo por mudanças comum a muitos países ibero-americanos, recém-independentes, que buscavam consolidar seus projetos de nação e encontrar saídas/modelos de desenvolvimento ante

\footnotetext{
* Professor Adjunto do Departamento de História Universidade Federal do Tocantins (UFT). Pós-doutorando em Antropologia Visual na Universidade Federal do Rio Grande do Norte (UFRN). Doutor em História pela Universidade Federal de Santa Catarina (UFSC).

E-mail: <maarraes@gmail.com>.

** Licenciado em História pela Universidade Federal do Tocantins (UFT). E-mail: <falcaomatheus.7@gmail.com>.
} 
as estruturas coloniais herdadas do passado. No que diz respeito à modernização da malha urbana, Almandoz (2007) aponta três vertentes principais que ocorreram nas cidades da Ibero-América, que são: as reformas sanitárias, as propostas de renovação urbana e a expansão residencial, cada qual com suas especificidades. Contudo, cabe salientar que, até quando foram levadas a cabo de forma isolada, essas vertentes modernizantes espelhavam um mesmo princípio técnico-estéticopolítico, como veremos.

Portanto, as reformas urbanas ocorridas em diversas grandes cidades da América Ibérica no final do Século XIX para o Século XX, mais que frutos preferenciais ou exclusivos da mudança de regimes ou tradição política, decorreram de uma lógica comum à modernidade. Assim, parece correto afirmar que, no caso especificamente brasileiro, não foi o advento da República que produziu as transformações urbanas, mas, inversamente, o desejo de modernidade que possibilitou a chegada da República.

Essa especificidade, contudo, não será o tema deste texto e serve apenas de cenário para o debate que queremos desenvolver. $\mathrm{O}$ que propomos é demonstrar como a modernidade fez emergir, junto com o desejo de renovação, uma lógica técnico-política condensada em princípios estéticos de caráter socialmente excludente. Procuraremos, então, estabelecer uma breve narrativa do contexto histórico em que ocorreram transformações urbanas no início da modernidade ibero-americana pontuando a presença de um projeto técnico-político norteador dos princípios estéticos ali presentes. Por fim, cabe salientar que este é um texto de caráter provocativo, escrito de forma semitelegráfica. Não objetivamos discutir tais questões conceitualmente, apenas (d)enunciá-las para concluir com um antigo alerta Benjaminiano.A virada do Século XIX para o XX foi marcada por significativas rupturas nas estruturas não somente econômica e política mas também nas bases social e cultural da sociedade ocidental como um todo. A consolidação da modernidade provocou novos arranjos políticos, a reestruturação das bases produtivas e o reordenamento da balança de poder mundial. Aliado a isso, e muitas vezes, como resposta a esses processos, assistiu-se à instauração de novos paradigmas científicos, uma crescente organização dos trabalhadores e uma reformulação das características técnico-sociais das cidades com novas lógicas urbanísticas de aceleração da vida e controle social. Modernizavam-se as cidades e as populações. Segundo Beck, Guiddens e Lash (2000, p. 2): "Modernização [...] significa, no fundo, primeiro o descontextualizar e segundo o recontextualizar das formas sociais tradicionais pelas formas industriais".

Os países da América Ibérica, que, nesse período, haviam, em sua grande maioria, recémconquistado sua independência política, ainda buscavam saídas para os problemas herdados do colonialismo e, portanto, viam nos arranjos das grandes potências hegemônicas modelos a serem seguidos para sua integração à lógica das sociedades industriais. Assim, pensar no processo de modernização na América Latina na virada do Século XIX para o XX implica admitir que esta dinâmica de recontextualização se atrelava a um âmbito maior e que se apresentava sob a égide de duas perspectivas distintas: a modernidade como momento histórico e a modernidade enquanto conceito estético. Para Calinescu (1991), essas duas modernidades se relacionavam de modo, ora antagônico e ora complementar, e representavam, a primeira delas, o resultado da euforia ligada às inovações tecnológico-científicas que ganhavam força bem como a dinâmica capitalista das revoluções industriais ascendente e irredutível; já a segunda modernidade

[...] estaba desde sus principios románticos inclinada hacia actitudes radicalmente antiburguesas. Estaba asqueada de la escala de valores de la clase media y expresaba su disgusto con los médios más diversos, desde la rebelión, la anarquía y el apocalipsis, hasta el aristocrático autoexilio. De modo que, más que sus aspiraciones positivas (que a menudo tienen poco en común), lo que define la modernidad cultural es su franco rechazado de la modernidad burguesa, su consuntiva pasión negativa. (CALINESCU, 1991, p. 51). 
Dessa forma, nota-se na modernidade enquanto momento histórico o ideal do progresso e do racionalismo. Pode-se afirmar que é esse o espírito que norteará as transformações urbanas na América latina, já que os reordenamentos urbanos típicos do fim do Século XIX propunham a transposição dos anseios que se tinham de modelar a sociedade em um projeto que deveria abarcar não apenas a estrutura física das cidades, como também os seus habitantes. Por essa razão, tanto na Europa quanto na América Ibérica, os desafios das reformas urbanas giraram em torno também do que deveria ser deixado, edificações ou vias ou que não eram compatíveis com o projeto de modernização ou que representavam "riscos" ao que se acreditava ser o ideal. As ideias norteadoras eimpulsionadoras dessas reformas se inspirariam no chamado "urbanismo acadêmico", proeminente em Paris na chamada École Française d'Urbanisme. Desta escola, diversos urbanistas teriam sido convidados a colaborar em projetos em cidades como Montevideo, Cidade do México, Havana, Caracas, São Paulo e Buenos Aires (ALMANDOZ, 2007, p. 63-66). ${ }^{1}$

Bem em sintonia com o paradigma cientificista do período, as reformas urbanas viriam também acompanhadas das chamadas reformas higienistas:

Ao lado dos desafios gerados pelas novas invenções técnicas, com destaque para a radical transformação do território impulsionada pela implantação das ferrovias, ganhavam corpo os questionamentos dos higienistas sobre a salubridade urbana e a busca de soluções para remediar os problemas sanitários das cidades industriais. Nesse contexto, questões como a proliferação de epidemias, o congestionamento das cidades, a inexistência de regras para o uso dos terrenos e até mesmo o tratamento de detritos e contaminação dos rios, ocupavam o centro dos debates e impulsionavam a elaboração dos primeiros relatórios sanitários, propostas legislativas e intervenções práticas sobre o tecido urbano preexistente. (RUFINONI, 2012, p. 11).

Partindo de uma atualidade dos princípios norteadores do urbanismo, vemos que as reformas urbanas deveriam se tratar de "[...] una etapa política en un proceso que busca mejorar el funcionamiento económico del país, alcanzar uma mayor justicia social y adecuar las ciudades a sus complejas funciones mediante una redistribución del poder politico y de los recursos" (HARDOY; MORENO, 1972, p. 6). No entanto, tais princípios não estavam presentes no paradigma cientificista do período analisado e, logicamente, não foram levados em conta nos casos hegemônicos das reformas urbanas ibero-americanas.

Considerando-se a modernização do Rio de Janeiro, por exemplo, citamos parte do discurso de Marcelo Mendonça, notável engenheiro e favorável às reformas vigentes. Acerca dos cortiços, Mendonça (1931, p. 141) afirma:

Visitar os cortiços da Capital Federal é suficiente para se ter uma visão clara deste problema. Deles, podemos dizer, vêm todas as misérias morais e materiais e todos os vícios. Nos cortiços têm tuberculose e alcoolismo. Lá os baixos instintos se desenvolvem. Lutar contra os cortiços é tomar parte em uma batalha para elevar a moralidade e melhorar a saúde física da raça. Este meio é geralmente ocupado pela classe trabalhadora, a classe que mais especialmente precisa de mais higiene física e moral.

Vê-se, assim, que a avassaladora modernização do período em questão buscava pautar-se em preceitos científicos para atingir não apenas um ideal estético, mas também, político, de controle social. Tal processo, portanto, é fundado na primeira modernidade definida por Calinescu, ao cultuar os princípios da razão, a doutrina do progresso, a confiança nas possibilidades da ciência e da tecnologia, sendo a segunda modernidade, a cultural, conflitiva com esta, forjando, assim, um alter ego da primeira, o que se veria no engajamento das vanguardas artísticas e nos movimentos de Arte Moderna, críticos à lógica técnico-científica do período, desenvolvidos, por exemplo, no Muralismo Mexicano, no Modernismo Brasileiro pós-1922, e na força de ideias de periódicos como Sur e Martín Fierro na Argentina. 
Situação análoga à sofrida pelos cortiços do Rio de Janeiro, foi também sentida na Argentina com os chamados convetillos, habitados por operários que tinham de lidar com a adaptação ao ambiente urbano. Aliás, a reconfiguração das populações da Ibero-América, acentuadamente rurais se considerarmos o início Século XIX, chama a atenção pelo enorme fluxo migratório e por certo inchaço populacional nos grandes centros, movimento vivido na Europa um século antes de forma mais lenta. Conforme aponta Almandoz (2007, p. 61):

Como en otras regiones del hoy llamado Tercer Mundo, la acelerada urbanización de América Latina en el siglo XX acentuó las concentraciones de un mapa que contrastaba con la dispersión y el atraso rurales. Atiborradas de migrantes campesinos y foráneos, antiguas capitales coloniales y urbes emergentes pronto alcanzaron magnitudes que rivalizaban con metrópolis europeas y norteamericanas. Buenos Aires saltó de 663.000 habitantes en 1895 a 2.178.000 en 1932; Santiago, de 333.000 en 1907 a 696.000 en 1930; y Ciudad de México, de 328.000 en 1908 a 1.049 .000 en 1933. Caso análogo al explosivo crecimiento de ciudades industriales como Manchester y Chicago, São Paulo pasó de 240.000 habitantes en 1900 a 579.000 en 1920 y 1.075 .000 en 1930.

$\mathrm{O}$ vertiginoso crescimento nesses grandes centros forma uma massa heterogênea e dispersa, que passará a se mobilizar em torno de movimentos sociais tais como o sindicalismo e o sufragismo, bem como evidenciará as profundas desigualdades sociais marcadamente percebidas nas disparidades entre os padrões de moradias; bairros abastados e repletos de integrantes de uma aristocracia rural da agroexportação, tais como os barões do café no Brasil, nada se assemelhavam aos cortiços e às construções improvisadas e precárias, inclusive do ponto de vista da higiene e saneamento, dos menos favorecidos. Almandoz (2007) traz o exemplo de uma tendência urbanística vinda da Inglaterra e incorporada em cidades como São
Paulo, Caracas e Havana: os chamados "bairros jardim", que acompanhariam o crescente uso do automóvel entre este grupo social e teria gerado bairros como o de Higienópolis, cujo nome remonta às aspirações e aos ideais deste período.

Tais transformações revelam os princípios norteadores da modernidade e os limites sociais de alcance dessas ações que tinham a construção das cidades como um projeto de civilidade e progresso que, por sua vez, era parte integrante da busca por efetivação e consolidação dos projetos de nação.

Assim, a chegada do Século XX com o espírito da Belle Époque trazia aos países iberoamericanos a idealização de algo; as reformas urbanas representariam assim a possibilidade de se chegar a esse arquétipo, bem como a oportunidade de superar o arcaísmo e a inércia de um passado tido como inexpressivo e atrasado. Essas aspirações passaram a povoar o imaginário de muitos, inclusive de uma aristocracia ascendente no Brasil, como a aristocracia paulista do café, acostumada ao ambiente rural. Conforme nos apresenta Doin et al. (2007, p. 94), durante o término do Século XIX e princípio do Século XX,

[...] muitos homens no interior paulista tinham seus sonhos povoados por desejos como o de viver um grande amor em Paris, desfrutar de seus cafés e cabarets, passear pelas suas ruas olhando as vitrines das butiques e admirando a luz elétrica, entre outras novidades técnicas e materiais. Seguindo as reflexões de Eric Hobsbawm, poderíamos dizer que tais personagens eram lançadas no "drama do progresso, a palavra-chave da época: maciço, iluminado, seguro de si mesmo, satisfeito, mas acima de tudo, inevitável”.

Essa busca por transformação e superação das estruturas do presente pode ser notada, por exemplo, no ideário e na obra de nomes como Monteiro Lobato. Para o autor, seria necessária a incorporação do espírito pungente estadunidense. Admirador confesso de Ford, Lobato queria a 
modernização do Jeca-Tatu. Denuncia-se em sua obra uma

[...] oposição entre a "expansão assombrosa dos Estados Unidos" e o "marasmo brasileiro", oposição entre a cultura de "cérebros velhos", de tradição europeia, e "cérebro de Henry Ford". A raça que habita o Brasil "é o velhíssimo português misturado com o arquivelho africano, mais o venerável pelevermelha" "É moço o povo americano". Assim, Monteiro Lobato contrapunha, uma ordem cultural negativa [...] a uma ordem positiva [...]. O tema trabalhado por Monteiro Lobato, criador do JecaTatu, típico brasileiro a ser investido pela eugenia, em Problema Vital, era o da "decadência biológica do homem brasileiro", cuja saída seria o saneamento e a higienização das condições de vida da população. Monteiro Lobato acreditava na eficiência e na propriedade das políticas eugênicas para o progresso nacional, inseridas no âmbito das ações de saneamento. (FLORES, 2007, p. 382383).

Vê-se, aí, de forma clara, uma estetização da política, um relacionamento entre as práticas técnico-políticas e os ideais estéticos. O progresso desejado por Lobato, com base nos princípios do Americanismo, escancarava as cidades enquanto palco para se ensaiar as transformações técnicas e o ideal estético dos Estados Unidos, transformandoas em uma esteira de produção. Contudo, nos dois casos, veem-se projetos de nação irmanados às transformações científico-técnicas, sendo os centros urbanos marcos deste processo: “[...] a cidade começa a ser vista como motor da modernização social, em íntima relação com as forças produtivas e com a consolidação dos poderes políticos centralizados" (GORELIK, 2005, p. 117). Desse modo, o modelo europeu e o estadunidense, apesar de suspensos em princípios comuns, apresentavam distinções sensíveis. O primeiro deles traria um modelo estético arquetípico e velado, atrelado às estruturas físicas; a segunda, um espírito efusivo, expansivo e explícito em seu ideal estético, como vemos em Lobato. O modelo hegemônico implantado em fins do Século XIX e início do Século XX na América Ibérica, contudo, mostrou-se ligado ao modelo Europeu, menos explícito em seus princípios estéticos, ainda que ali eles estivessem presentes. Isso mudaria no decorrer do século, mais especificamente durante a chamada Política da Boa Vizinhança, período, contudo, que escapa ao escopo deste artigo. ${ }^{2}$

Outro ponto a ser aqui citado éa transposição entre o discurso, os ideais e a prática das reformas urbanas. Essa relação entre planejamento urbano e projeto de poder pode ser percebida pelas escolhas que se faz e pela forma como se estrutura uma cidade, privilegiando ou não determinados grupos e espaços. Outtes (2014, p. 718) assevera que

[...] decisões de zoneamento, como o uso restrito de áreas, proibição de estacionamento em certas ruas, alocação de partes de um litoral para descarga de navios em vez de natação e banhos - tudo tem um efeito sobre a liberdade individual. Se a prisão é o lugar no qual a liberdade é completamente suprimida, uma zona urbana restritiva é um lugar onde a liberdade é pelo menos ligeiramente diminuída.

Conforme Sandra Pesavento (1999, p. 93):

Uma cidade é, sem dúvida, antes de tudo, uma materialidade de espaços construídos e vazios, assim como é um tecido de relações sociais, mas o que importa, na produção do seu imaginário social, é a atribuição de sentido que lhe é dado, de forma individual e coletiva, pelos indivíduos que nela habitam.

Tais assertivas reforçam a ideia de que a estrutura das cidades, (re)pensadas neste momento de modernização, corroborariam e legitimariam projetos solidificados de estados-nação, que, no caso da América Ibérica, eram bastante recentes se considerarmos a efetivação das independências dos países da região após o desgaste de parte da estrutura colonial e mercantilista que teria vigorados nos séculos anteriores.

Um dos exemplos a ser citado neste sentido é o caso argentino. Como destaca Lenz (2012, p. 12):

Em 1880 Julio Argentino Roca assumiu como presidente da Nação argentina 
e Buenos Aires foi declarada capital federal do país e sede de suas máximas autoridades. Assim, nos anos oitenta a cidade de Buenos Aires, definiu sua posição nacional ao ser federalizada, reforçando o seu caráter de centro econômico ao consolidar-se como cabeceira de linhas férreas e porto principal da Argentina. A cidade de Buenos Aires não era só era a capital política do país, mas também a financeira e a econômica, e durante muito tempo o seu único grande foco cultural. Na sua transformação houve a busca de seus conteúdos em fontes europeias, e resultou um exemplo a imitar pelas suas cidades do interior.

Desse modo, Buenos Aires seria o marco representativo de um programa estético e as suas transformações urbanísticas viriam cumprir a realização deste. Esta dinâmica de conformidade entre espaço urbano e projeto de poder é sentida de diversas formas em todos os grandes centros da América Latina deste momento histórico, partindose do ideal das cidades e das tendências europeias.

Convém destacar aqui que as transformações urbanas traziam consigo o conflito entre o passado e o presente, o antigo e o novo. A demolição de antigos "artefatos" arquitetônicos para dar lugar ao imediatismo que o presente urgia. Curiosamente, da mesma forma que isso se nota nas reformas da América Ibérica, também se confirma nas anteriores experiências de Paris e de outras capitais da Europa. Ali:

O conjunto de reformas urbanas realizadas a partir da década de 1850 , ao propor a reestruturação viária da cidade por meio da sobreposição de uma nova malha de vias largas e retilíneas sobre a antiga Paris, provocou a destruição de grande parte dos bairros medievais e colocou em pauta, pela primeira vez nesta escala, os problemas da relação antigo-novo na intervenção sobre a cidade antiga (RUFINONI, 2012, p. 11).

Diante do exposto, parece ser seguro afirmar que a modernidade afirmou um projeto hegemônico de caráter técnico-político no qual estava contido um programa estético. Por projeto, estamos compreendendo um agenciamento que se abre as contingências de um futuro incerto e por programa um "[...] programa tecnológico de governo, como indicara Foucault, que exige previsibilidade para garantir os intercâmbios generalizados que regulam um sistema" (ULM, 2018, p. 3). Nesse contexto, as cidades abriram-se enquanto instrumentos, veículos de agenciamento social do projeto burguês moderno. A cidade, tornada como mídia de expressão dessa modernidade, executa a sua programação. Dito de outro modo, as transformações urbanas puseram em prática um devir estético que afirmava uma prática técnico-política de controle social. Isso ocorreu nas principais cidades industrializadas da América Ibérica, enquanto espelho de outros centros ocidentais.

Como nos diz Walter Benjamin (1985), a modernidade abriu às massas a possibilidade de expressão de sua natureza. A explosão demográfica e o crescimento das cidades do período Industrial foram acompanhados de uma maior visibilização das massas, tornada possível com os transportes em massa, a comunicação de massa, e as próprias reformas urbanas, que ampliam as ruas e dão maior espaço à circulação de pessoas. Por outro lado, os direitos das massas não podem ser expressos ou reivindicados. O transporte é caro e limitado a algumas regiões, o acesso aos jornais ou a voz dada por eles pertencem a alguns, as ruas amplas também facilitam a repressão de movimentos sociais. Os direitos pertencem apenas a alguns. Os usos são restritos. Portanto, o agenciamento da modernidade possui, em si, um programa tecnoestético de controle das massas, de normalização das classes subalternas. Cabe salientar que as resistências se fizeram presentes, procurando instituir projetos e programas contra-hegemônicos, cuja análise, contudo, ficará para outro estudo.

Para finalizar, retomamos a dupla concepção de modernidade de Calinescu (2016), apresentada acima, na tentativa de encontrar irrupções e possibilidades de resistência a esses agenciamentos do programa tecnológico da modernidade. Se a primeira, programática, enquadra, limita, normatiza a partir dos dispositivos técnico-políticos aqui discutidos, a segunda, a modernidade prescrita pelas 
artes, inscreve possíveis falhas desses agenciamentos. A arte modernista é uma forma de resistência ao projeto moderno, tentando interromper os agenciamentos sociais da modernidade com outros princípios. O projeto que se realiza é extremamente perigoso, protofascista, eliminando do campo do possível todos os seres sociais que não fazem parte desse programa. Algumas vanguardas e muitos movimentos da Arte Moderna na América Latina procuram instaurar campos de inscrição das massas na realidade histórico-artística. Assim o fazem, por exemplo, o muralismo Mexicano, que eterniza uma memória social da Revolução de 1910. Em outra ordem, podemos também afirmar que a busca da brasilidade no Modernismo brasileiro, ainda que de forma limitada, abriu algum espaço para a expressão de outras formas e estéticas sociais não hegemônicas.

O urbanismo, desejado e visto por muitos enquanto expressão artística de preceitos científicos, não se fez assim no contexto aqui enunciado. Ao menos não dentro do segundo conceito de modernidade de Calinescu (1991). Ao contrário, a ciência do reaparelhamento urbano das cidades Ibero-Americanas em fins do Século XIX e inícios do Século XX expressou categoricamente os preceitos técnicos e políticos da modernidade, executou tal qual a programação estética ali presente, garantindo espaço para o belo, para o progresso e para o veloz ao mesmo tempo em que limitava a vida, a expressão e as possibilidades de existir das massas. Se foi arte, foi arte enquadrada, arte pela arte, que em nada interrompeu os agenciamentos da modernidade.

Para finalizar, cabe relembrar a atualidade do alerta emitido por Benjamin (1985, p. 196, grifos no original):

"Fiat ars, pereat mundus" [criar a arte, destruir o mundo], diz o fascismo e espera que a guerra proporcione a satisfação artística de uma percepção sensível modificada pela técnica, como faz Marinetti. É a forma mais perfeita do art pour l'art. Na época de Homero, a humanidade oferecia-se em espetáculo para si mesma. Sua auto-alienação atingiu o ponto que lhe permite viver sua própria destruição como um prazer estético de primeira ordem. Eis a estetização da política, como a pratica o fascismo. O comunismo responde com a politização da arte.

\section{Notas}

$1 \mathrm{O}$ tema de modernização aliado às reformas urbanas, ainda que relativamente pouco explorado, dispõe de uma consolidada bibliografia de estudos que as analisaram sob diversas perspectivas e diversos escopos, sejam eles regionais, nacionais ou de maior escala. Cabe mencionar que, para além dos principais centros urbanos iberoamericanos, o impulso modernizador norteou pequenas transformações em uma escala micro manifesta em diversas localidades menores e distantes dos principais centros econômicos. Em um país de vastas dimensões e distintas experiências históricas regionais como o Brasil, por exemplo, encontram-se estudos e levantamentos que relacionam o impulso da modernização mesmo em pequenas cidades nos mais afastados rincões ou mesmo em capitais mais distantes do litoral, região esta mais pujante economicamente desde a colonização (HOLANDA, 1995). Nosso objetivo aqui não reside em explicitar estes casos pontuais, mas sim em perceber uma lógica hegemônica por trás deles. Cabe salientar, contudo, que como toda hegemonia, esses princípios contaram com diversas apropriações/adaptações regionais, bem como com resistências contra-hegemônicas.

2 Para conhecer mais detalhes a respeito das transformações urbanas, lógicas e tecnopolíticas do período da Política da Boa Vizinhança, vide: Arraes, 2018.

\section{Referências}

ALMANDOZ, Arturo. Modernización urbanística en América Latina. Luminarias extranjeras y cambios disciplinares, 1900-1960. Iberoamericana, v. 7 , n. 27 , p. 59-81, 2007.

ARRAES, Marcos Alexandre de Melo Santiago. O tempo corpóreo e sensível da cidade: um estudo da modernidade no Recife a partir da literatura. Verbo de Minas, Juiz de Fora, v. 19, n. 34, p. 123-142, ago./ dez. 2018.

BECK, Ulrich; GIDDENS, Anthony; LASH, Scott. Modernização Reflexiva: Política, Tradição e Estética na Ordem Social Moderna. Tradução de Maria Amélia Augusto. Oeiras: Celta Editora, 2000.

BENJAMIN, Walter. Obras escolhidas. Volume 1: Magia, técnica, arte e política. Ensaios sobre 
literatura e história da cultura. São Paulo: Brasiliense, 1985.

CALINESCU, Matei. Cincocaras de la modernidad: Modernismo, vanguardia, decadencia, kitsch, postmodernismo. Tradução de Francisco Rodríguez Martín. Madrid: Tecnos Editorial, 2016.

DOIN, José Evaldo de Mello; PERINELLI NETO, Humberto; PAZIANI, Rodrigo Ribeiro; PACANO, Fábio Augusto. A Belle Époque caipira: problematizações e oportunidades interpretativas da modernidade e urbanização no mundo do café (1852-1930) - a proposta do Cemumc. Revista Brasileira de História, São Paulo, v. 27, n. 53, p. 91122, 2007.

FLORES, Maria Bernadete Ramos. Tecnologia e Estética do Racismo: Ciência e Arte na Política da Beleza. Chapecó: Argos, 2008.

GORELIK, Adrián. A produção da "cidade latinoamericana". Tradução de Fernanda Arêas Peixoto. Tempo Social, revista de sociologia da USP, São Paulo, v. 17, n. 1, p. 111-133, 2005.

HARDOY, Jorge E.; MORENO, Oscar A. Primeros Pasos de la Reforma Urbana en América Latina. Revista Eure, Santiago de Chile, v. 2, n. 4, p. 83-100, 1972.
HOLANDA, Sérgio Buarque de. Raízes do Brasil. São Paulo: Companhia das Letras, 1995.

LENZ, Maria Heloisa. A Buenos Aires do século XIX: a metrópole da Belle Époque argentina. Fênix - Revista de História e estudos culturais, Porto Alegre, v. 9, n. 1, p. 1-19, 2012.

MENDONÇA, Marcelo. Taylor de Casas populares: cidades jardins. In: INSTITUTO DE ENGENHARIA DE SÃO PAULO. Annaes do $\mathbf{1}^{\circ}$ Congresso de Habitação. São Paulo: Escolas Profissionais do Lyceu Coração de Jesus, 1931. p. 139-147.OUTTES, Joel. Cidade e Habitação na América Latina (18901945): uma perspectiva foucaultiana. Urbana, Campinas, v. 6, n. 8, p. 716-739, 2014.

PESAVENTO, Sandra Jatahy. O Imaginário da Cidade. Porto Alegre: Editora da UFRGS, 1999.

RUFINONI, Manoela Rossinetti. Os estudos de estética urbana e a percepção da cidade artefato no alvorecer do século XX. Revista CPC, São Paulo, n. 14, p. 6-29, 2012.

ULM, Hernán. La distancia y el instante. Técnica, estética y política en el devenir digital. [s. n.]: [s. 1.]: 2018. [Texto inédito, cedido pelo autor]. 